\title{
I ntrodução aos Conceitos de Velocidade Máxima e de Atividade Específica de Enzimas
}

\author{
(Introducing the Concepts of Maximal Velocity and Specific Activity of Enzymes)
}

\author{
Autores: M. Lucia Bianconi \\ Afiliação:Departamento de Bioquímica Médica - ICB - UFRJ \\ bianconi@bioqmed.ufrj.br
}

The understanding of the kinetic parameters of an enzymatic reaction for first time students is usually difficult. Here is shown a simple way to introduce the concepts of maximum rate (Vmax) and specific activity or turnover number of an enzyme. Different simulations with different symbols representing the enzyme, the substrates and products are one, were the concentration of each species is changed at a given condition. At the beginning of the task, it is defined that one enzyme E catalyses the reaction with the substrate $\mathrm{S}$, giving rise to one product $\mathrm{P}$ after one minute of reaction. This long time is used just to simplify the exercise. After that, several situations are presented, were the concentrations of $E$ or $\mathrm{S}$ is changed, but the above definition is always maintained. After that, it is possible for the student to see that Vmax depends on the enzyme concentration, whereas the specific activity is constant and characteristic for an enzyme.

\section{I ntrodução}

A definição dos parâmetros cinéticos de reações catalisadas por enzimas que seguem o modelo de MichaelisMenten não é muito simples para o estudante. Compreender que a velocidade máxima (Vmax) de uma reação é uma "variável", já que depende da concentração de enzimas, não é simples apenas mostrando as equações matemáticas que levam à dedução da equação de Michaelis-Menten.

Procuramos usar um sistema simples em sala de aula, com desenhos que representam enzimas, substratos e produtos para ilustrar a reação enzimática. Seguindo passo a passo, com os alunos, as diferentes condições onde adicionamos enzimas ou substratos ao sistema, é possível fazer com que compreendam o que é Vmax e a diferença entre Vmax e atividade específica de forma simples. Dessa forma, o aluno entende facilmente que a Vmax depende não só da concentração de substrato como, também, varia com a quantidade de enzima adicionada ao sistema, o que não ocorre com a atividade específica.

\section{Métodos}

Neste método, procuramos fazer com que os alunos acompanhem cada passo, participando do processo. Procure fazer com que eles respondam as questões em voz alta, juntos, de preferência.

Em primeiro lugar, definimos um sistema onde UMA enzima leva UM minuto para transformar UM substrato em UM produto, mostrando o esquema abaixo: 


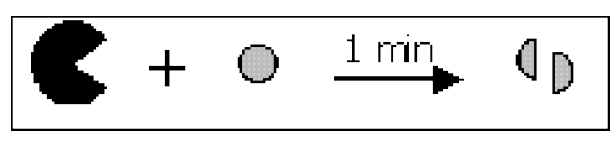

Depois, mostramos um sistema contendo apenas uma enzima, e uma quantidade qualquer de substrato [Condição 2], lembrando que a enzima e os substratos nessa situação obedecem a definição dada na Condição 1.

\section{[Condição 2]}

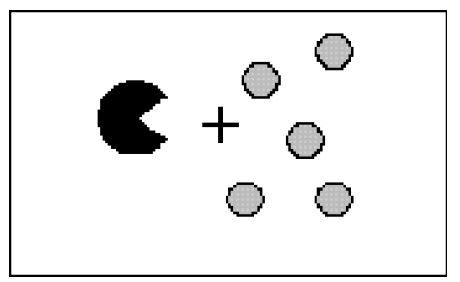

Daqui em diante, todos os passos devem ter a participação ativa dos alunos que respondem como cada modificação introduzida deve afetar o sistema.

Pergunta-se: "Quantos produtos são formados após 1 minuto de reação?"

Enquanto os alunos chegam à conclusão de que, apesar de aumentarmos a quantidade de substrato, após 1 minuto de reação, teremos apenas 1 produto formado como no esquema da Condição 1, incluindo no quadro um símbolo para o produto:

[3]

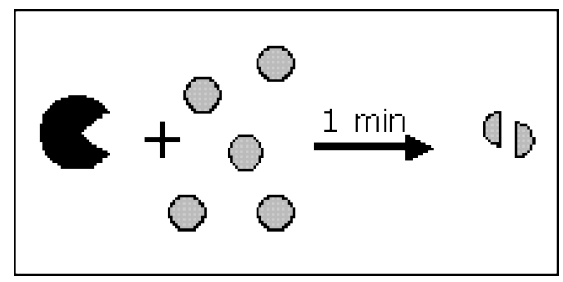

Podemos continuar com o mesmo sistema, adicionando mais substratos e chegando a mesma quantidade de produto após 1 minuto de reação. Agora, é possível definir a velocidade desta reação como:

$$
\text { Velocidade }=\frac{1}{\text { min }}
$$

Em seguida, tiramos todos os substratos e aumentamos o número de enzimas no sistema para 6 , por exemplo. A quantidade de enzimas no sistema não importa e, sim, o raciocínio que se segue em cada passo. Adicionando o substrato, um a um, perguntamos aos alunos quantos produtos formaram em cada adição, após 1 minuto de reação.

\begin{tabular}{|l|l|l|}
\hline $\begin{array}{l}\text { Quando apenas } \\
1 \text { substrato é } \\
\text { adicionado... }\end{array}$ & $\begin{array}{c}\text {...após 1 minuto, } \\
\text { forma-se 1 produto. }\end{array}$ \\
\hline
\end{tabular}

\begin{tabular}{|c|c|c|}
\hline $\begin{array}{c}\text { Foram } \\
\text { adicionados } 2 \\
\text { substratos... }\end{array}$ & $\mathbf{3}$ & $\begin{array}{c}\text { formando } 2 \text { produtos } \\
\text { após } 1 \text { minuto de } \\
\text { reação. }\end{array}$ \\
\hline
\end{tabular}




\begin{tabular}{|c|c|c|c|}
$\begin{array}{c}\text { Foram } \\
\text { adicionados } 3 \\
\text { substratos... }\end{array}$ & $\begin{array}{c}\text { formando } 3 \text { produtos } \\
\text { após } 1 \text { minuto de } \\
\text { reação. }\end{array}$ \\
\hline
\end{tabular}

E assim, sucessivamente, até chegarmos a 6 substratos para, em seguida, continuarmos as adições de substratos mostrando que a velocidade da reação já não varia mais.

\begin{tabular}{|c|c|c|}
\hline $\begin{array}{c}\text { Adicionando } 6 \\
\text { substratos... }\end{array}$ & 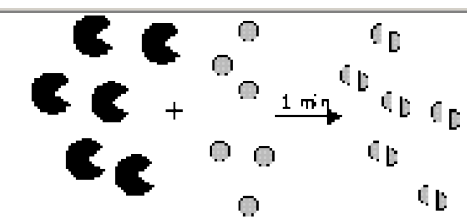 & $\begin{array}{c}\text {... formam-se } 6 \\
\text { produtos após } 1 \text { minuto } \\
\text { de reação. }\end{array}$ \\
\hline
\end{tabular}

\begin{tabular}{|c|c|c|}
\hline $\begin{array}{c}\text { E quando } \\
\text { adicionamos } 7,8 \\
\text { ou } 12 \\
\text { substratos, por } \\
\text { exemplo.... }\end{array}$ & 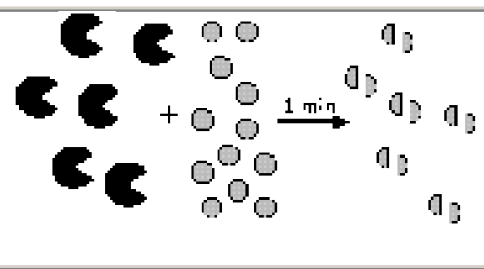 & $\begin{array}{l}\text {... continuamos obtendo } \\
\text { apenas } 6 \text { produtos após } \\
1 \text { minuto de reação! }\end{array}$ \\
\hline
\end{tabular}

Repetimos o mesmo procedimento para dois casos distintos onde teremos, por exemplo, 3 ou 9 enzimas no sistema. Em cada caso, chamamos a atenção para o fato de que foi atingida uma Velocidade Máxima de reação. Sendo assim, chegaremos a uma relação que mostra que a velocidade máxima atingida nesses sistemas depende da quantidade inicial de enzimas:

(I) 6 enzimas à 6 produtos em 1 minuto $(5 \mathrm{P} / \mathrm{min})$

(II) 3 enzimas à 3 produtos em 1 minuto $(3 \mathrm{P} / \mathrm{min})$

(III) 9 enzimas à 9 produtos em 1 minuto (9P/min)

Ou seja, pode-se perceber que a velocidade máxima variou em cada caso mas que a variação foi proporcional à quantidade de enzimas no sistema. Portanto, a Velocidade Máxima é proporcional ao número de enzimas presentes no meio.

Assim que esse ponto fica bem claro, podemos prosseguir. Agora, usando as velocidades máximas atingidas em casa caso, mostramos a relação entre ela e a quantidade de enzimas, dessa forma:

Para 6 enzimas:

Velocidade $=\frac{G F}{\text { min }}$

Como precisamos de 6 enzimas para atingir essa velocidade, se dividirmos a velocidade pelo número de enzimas, chegamos à relação de $1 \mathrm{P} / \mathrm{min}$.

$$
\text { Velocidade }=\frac{G P}{\min } \cdot \frac{1}{6 E} \longrightarrow \frac{1 P}{\min }
$$

O mesmo ocorre nos outros casos:

Para 3 enzimas: 
Velocidade $=\frac{3 \mathrm{P}}{\min } \cdot \frac{1}{3 \mathrm{E}} \longrightarrow \frac{1 \mathrm{~F}}{\min }$

E para 9 enzimas:

Velocidade $=\frac{9 \mathrm{P}}{\text { miri }} \cdot \frac{1}{9 \mathrm{E}} \longrightarrow \frac{1 \mathrm{P}}{\text { mini }}$

Dessa forma, define-se Atividade Específica, já que cada enzima tem essa capacidade de transformar, em um minuto, apenas um substrato em um produto.

\section{Resultados}

A partir das condições estudadas, podemos usar os dados para criar gráficos de velocidade de reação (V) em função da concentração de substrato, e de $V$ em função da concentração de enzimas.

Enquanto são realizados os procedimentos de adição de substrato ao sistema contendo 6 enzimas, por exemplo, cria-se uma tabela no quadro, ao lado dos desenhos, com os valores de velocidade (V) obtidos para cada quantidade de substrato ([S]) adicionada (Tabela 1)

Tabela 1: Efeito da quantidade de substrato na velocidade da reação hipotética com 6 enzimas.

\begin{tabular}{|c|c|}
\hline [S] & $\mathbf{V}(\mathbf{P} / \mathbf{m i n})$ \\
\hline 1 & 1 \\
\hline 2 & 2 \\
\hline 3 & 3 \\
\hline 4 & 4 \\
\hline 5 & 5 \\
\hline 6 & 6 \\
\hline 8 & 6 \\
\hline 10 & 6 \\
\hline 12 & 6 \\
\hline 14 & 6 \\
\hline 16 & 6 \\
\hline
\end{tabular}

Em seguida, pede-se para que os alunos desenhem a curva de $\mathrm{V}$ em função de [S], usando os dados da Tabela 1, obtendo um gráfico como o da Figura 1. 


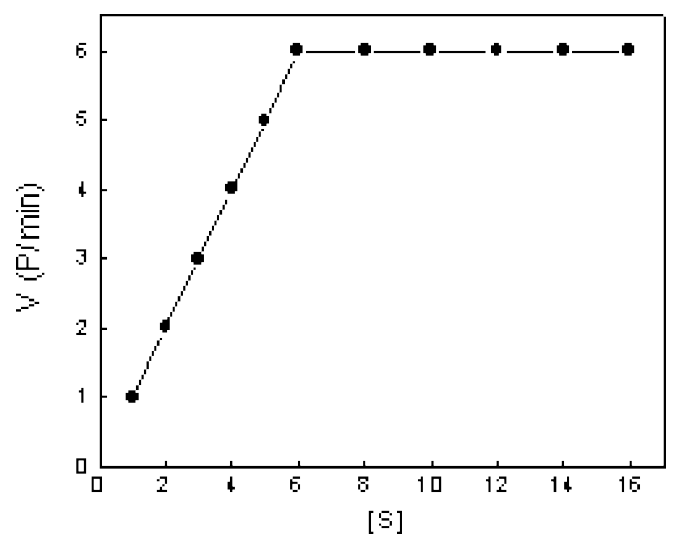

Figura 1: Efeito da concentração de substrato, [S], na velocidade da reação (V) catalisada por 6 enzimas como definido em Métodos.

Depois, criamos um gráfico que mostra a variação da velocidade máxima (Vmax) com a concentração de enzimas (Figura 2A) e outro da atividade específica em função da concentração de enzimas (Figura 2B).

\section{(A) (B)}
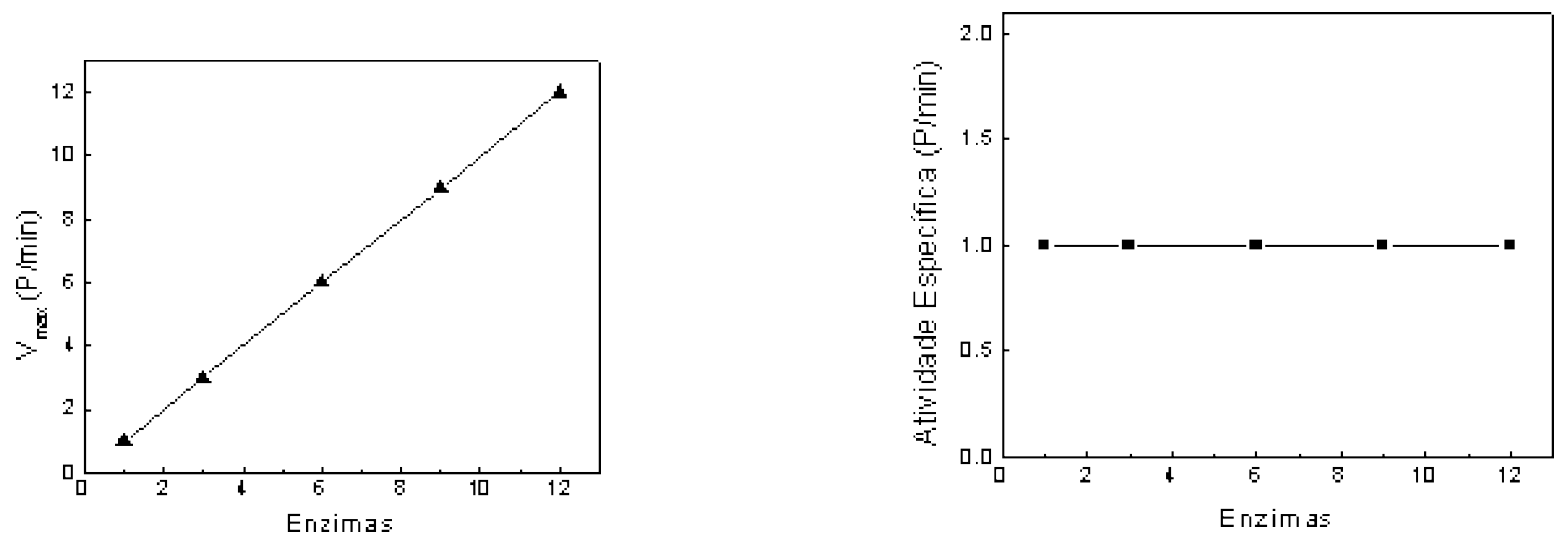

Figura 2: Efeito da concentração de enzimas na velocidade máxima (Vmax) da reação (A) e na atividade específica (B) dessa enzima, de acordo com os dados obtidos em "Métodos".

\section{Discussão}

Note que esse procedimento descrito em "Métodos" é simplista, ou seja, não leva em conta os equilíbrios de associação enzima-substrato. Como pode ser visto na Figura 1, a curva obtida para $\vee$ em função de [S], é diferente daquela observada para enzimas que obedecem o modelo de "Michaelis-Menten" (Figura 3). Mesmo assim, a construção da curva da Figura 1 é interessante para que o aluno se familiarize com o processo de criação de tabelas e gráficos.

Seria interessante desenvolver, na aula seguinte, a equação de Michaelis-Menten, definindo velocidade inicial (V0), introduzindo $\mathrm{Km}$ e mostrando como são os gráficos de $\mathrm{V} 0$ em função da concentração de substrato. O livro de bioquímica do Stryer (1) descreve com clareza cada etapa importante do modelo de Michaelis-Menten. 


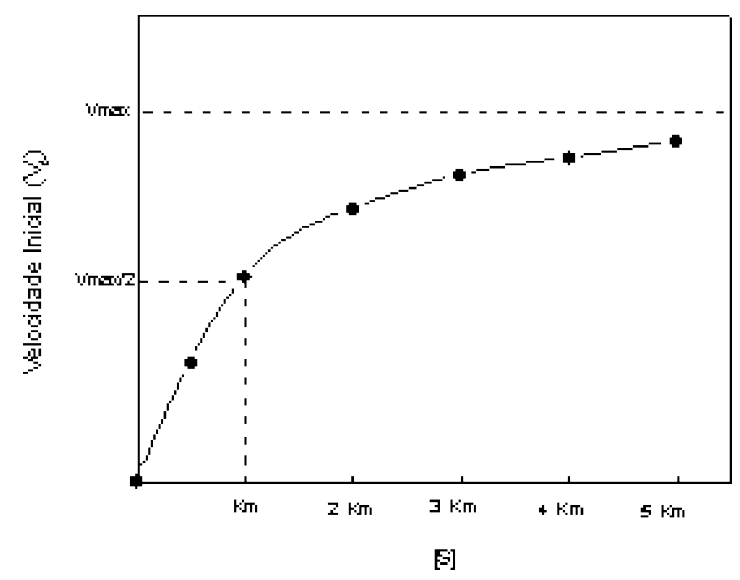

Figura 3: Gráfico representativo da velocidade inicial de reação (V0) em função da concentração de substrato para enzimas que obedecem o modelo de Michaelis-Menten.

\section{Referências Bibliográficas}

Stryer, L. (1988) Biochemistry, 3rd edition, W.H. Freeman and Company, New York 